\title{
Therapeutic Efficacy of Urtica dioica and Evening Primrose in Patients with Rheumatoid Arthritis: A Randomized Double-Blind, Placebo-Controlled Clinical Trial
}

\section{Bahareh Abd-Nikfarjam ( $\sim$ Nikfarjamm@gmail.com )}

Qazvin University of Medical Sciences https://orcid.org/0000-0003-4014-831X

\section{Mahnaz Abbasi}

Qazvin University of Medical Sciences

Mohammadreza Memarzadeh

Kashan University of Medical Sciences

\section{Seyed-Amir Farzam}

Qazvin University of Medical Sciences

\section{Azam Jamshidian}

Shahrekord University of Medical Science

Amirhossein Dolati-Somarin

Mashhad University of Medical Sciences

\section{Research article}

Keywords: Rheumatoid Arthritis, Urtica dioica, Evening Primrose Oil, Clinical Trial, DAS 28, IL-17, TAC

Posted Date: March 18th, 2021

DOl: https://doi.org/10.21203/rs.3.rs-309562/v1

License: (c) (i) This work is licensed under a Creative Commons Attribution 4.0 International License.

Read Full License

Version of Record: A version of this preprint was published at Journal of Herbal Medicine on February 1st, 2022. See the published version at https://doi.org/10.1016/j.hermed.2022.100556. 


\section{Abstract}

Introduction: Rheumatoid arthritis (RA) is a systemic inflammatory autoimmune disease. The pharmacological therapy of RA is often symptomatic to mitigate pain and inability with analgesics and drugs with defined side effects and risks. Complementary medicines might decrease the signs of RA and reduce the need for these medicines. In the present study, we investigated the anti-rheumatic, antiinflammatory and anti-oxidant effects of Urtica dioica and Evening Primrose Ogil (EPO), in patients with RA.

Methods: This randomized, double-blind, controlled trial involved 90 RA patients, and randomly assigned them into EPO, Urtica dioica, and placebo groups. The potential effect of these herbal medicines on Disease Activity Score (DAS) 28, Visual Analogue Scale (VAS), Total Anti-oxidant Capacity (TAC), IL-17, Rheumatoid Factor (RF), anti-cyclic citrullinated peptide antibodies (Anti-CCP), C Reactive Protein (CRP), and Erythrocyte Sedimentation Rate (ESR) before and after clinical trial were evaluated. The trial registration number is IRCT20201001048897N1.

Results: After a three month follow up, the mean values of DAS28, IL-17, TAC, RF, and CRP in EPO and Urtica dioica groups were significantly different from the placebo group. However, the VAS, Anti-CCP, and ESR at baseline and at the end of the study were not significantly different between the three groups. After the intervention, the within-group DAS28 in the EPO and Urtica dioica groups, and placebo group reduced significantly compared to the baseline.

Conclusion: Medicinal plants EPO and Urtica dioica were appeared to decrease inflammatory factors, and can improve the symptoms of RA. Thus, EPO and Urtica dioica have great potential as a complementary therapy in RA patients.

\section{Introduction}

Rheumatoid arthritis (RA) is a chronic systemic autoimmune disorder that affects women more than men, being commonly occurred in the middle ages. RA affects all populations, and worldwide, the incidence of RA is almost 3 cases per 10,000 people annually, and the prevalence rate is about 1\% (Guo et al., 2018).

RA characterized by an inflammatory polyarthritis that commonly involved the small joints (Guo et al., 2018), synovial inflammation, arthralgia, swelling, redness, autoantibody production, cartilage and bone damage, cardiovascular, pulmonary, and skeletal complications, that can cause progressive disability (Sung et al., 2019).

The risk of extra-articular symptoms development such as keratitis, pulmonary granulomas (rheumatoid nodules), pericarditis/pleuritis, and small-vessel vasculitis are increased in uncontrolled and severe RA (Guo et al., 2018). 
T lymphocytes, B lymphocytes, and cytokines (Tumor Necrosis Factor-alpha (TNF-a), IL-6, IL-1, and IL-17) have major roles in developing RA symptoms such as bone and cartilage destruction, and synovitis (Choy, 2012).

The etiology of RA is not clear exactly, it seems that Th1 and Th17 lymphocytes have important roles in the pathogenesis of RA. Th17 cells express the cytokines such as IL-17, IL-21, and IL-22, and have been shown to play a major role in the development of inflammation and joints injury in RA. Furthermore, the pro-inflammatory cytokine IL-23 has participated in the development and activation of Th17 lymphocytes and IL-17 expression. IL-17 is highly synthesized in the RA-affected synovium and synovial fluid. The cytokines, IL-17 and TNF- $a$ are activated in the RA synovial tissue and leading in the production of proinflammatory cytokines such as IL-6 and IL-8, and joint inflammation. IL-17 affects osteoclast differentiation by stimulating the expression of Receptor Activator of Nuclear Factor kappa-B Ligand (RANKL) on the surface of osteoblasts and synoviocytes. It has also been proposed that the Th17/Treg unbalance and the elevated level of IL-17 involved in the progression of RA. Previous studies have demo

nstrated a significant role for Th17 cells and IL-17 in the pathogenesis of inflammatory and ruinous patterns properties of joint and correlation with disease activity and severity (Al-Saadany et al., Taams, 2020, Robert and Miossec, 2019).

Several genetic loci are associated with RA include HLA-DRB1, signal transducer and activator of transcription 4 (STAT4), protein tyrosine phosphatase (PTPN22), peptidyl arginine deiminase type I, IV (PAD14), and cytotoxic T-lymphocyte antigen 4 (CTLA4) (Mclnnes and Schett, 2007, Viatte et al., 2013).

Several therapeutic remedies accessible for ameliorating RA symptoms have been used over the past 30 years. These treatments consist of non-steroidal anti-inflammatory drugs (NSAIDs), glucocorticoids, synthetic and biological disease-modifying anti-rheumatic drugs (DMARDs) include methotrexate and TNF inhibitors, IL-6 inhibitor, IL-6 receptor antibody, RANKL antibody, and B cell-depleting medications (anti-CD20 antibody)(Guo et al., 2018, Burmester and Pope, 2017).

In fact, prescription of NSAIDs and corticosteroids are effective in mitigating morning stiffness and pain but do not prevent disease progression (Guo et al., 2018). Although, traditional DMARDs usually cause side effects such as cytopenia, transaminase elevation, and poor tolerability. Moreover, another class of new medications, Janus kinase (JAK) pathways inhibitors, frequently have gastrointestinal side effects, lymphopenia, neutropenia, increased cholesterol, and more infections (Burmester and Pope, 2017).

Despite the wide variety of new medications, complete long-term disease improvement has not occurred in many RA patients, therefore more effective therapeutic solutions and new pharmacological interventions are needed for RA treatment (Guo et al., 2018).

While there is now no certain treatment for RA, the new cure purpose orientation is attaining a low disease activity state (LDAS). There are many scales for evaluating the disease activity like the Disease Activity 
Score using 28 joints (DAS28) (Ometto et al., 2010). Therefore, similar to other autoimmune disorders, no complete and definitive treatments for RA have been found so far.

Historically, medicinal plants have been used by humans as a traditional means of relieving several diseases. In spite of the considerable advances in the development of therapy, there is still a need for potent and efficient analgesic drugs. In this regard, it has been widely shown that many substances derived from plants play a relevant role in the process of development of new strategies to treat complaints related to pain (Calixto et al., 2000). Many researchers have been trying for a long time to find medications for RA from natural materials which have no or fewer side effects and toxicity. Herbal medicines are one of the paramount types of natural substances that have been investigated in this background. Medicinal plant interventions have been shown that have potential benefits in the treatment of RA. Numerous studies have demonstrated that many medicinal plants exert anti-inflammatory and anti-oxidant effects and have a potential role in the treatment of RA (Li et al., 2019).

Herbal medicines have been popular since antiquarian times, and nowadays they are commonly used in different types, including medicinal plants or their extracts universally (Petrovska, 2012, Forouzanfar and Hosseinzadeh, 2018, Ekor, 2014). Complementary and alternative medicines (CAMs), especially herbal remedies, are generally used by patients with RA. Worldwide, the prevalence of CAM consumption in RA patients is calculated to be $20-86 \%$ (Zhao et al., 2017).

Urtica dioica L. (stinging Nettle) is an herbal perennial plant, belongs to the family of Urticaceae and genus Urtica, and it is considered therapeutically interchangeable (Dhouibi et al., 2020). Numerous studies have confirmed the good effects of Urtica dioica in the world. Investigating the mechanisms underlying beneficial effects of Nettle in RA can open up a new horizon for new therapeutic strategies. Urtica extracts can be packaged according to the separation of effective ingredients for optimal therapeutic uses (AlShuwayeb and Al-Khatib, 2013). Previous studies have shown that leaf extract of Urtica dioica has inhibitory potential on pro-inflammatory transcription factor NF- $K B$, which is elevated in synovial fluid of RA patients (Riehemann et al., 1999). An aqueous extract of Nettle leaves suppresses the expression of IL-2 cytokine induced by phytohemagglutinins and that of IFN- $y$ in mononuclear cell culture in a dose-dependent manner. In contrast, increases the production of IL-4 by Th2 lymphocytes. Several studies have indicated that the extract of Nettle leaves inhibits the production of T cells cytokines and can prevent inflammation in autoimmune diseases like RA (Dhouibi et al., 2020).

Furthermore, a study conducted by Klingelhoefer et al. demonstrated the anti-inflammatory properties of Nettle against autoimmune diseases, such as RA (Klingelhoefer et al., 1999).

The Nettle is used traditionally as a diuretic, anti-hypertensive, anti-diabetic, hemostatic, anti-asthenia, anti-anemia, anti-spasmodic, anti-rheumatic, headaches, and chills (Bnouham et al., 2002). Nettle is also can treat spleen, renal and dermal diseases (Daoudi et al., 2008). Furthermore, root extracts act as vasodilators because of the endothelial NO release (Testai et al., 2002). The aqueous extract of aerial parts of the nettle shows anti-ulcer effects (Gülçin et al., 2004), , and anti-bacterial and anti-mycotic activities (Gülçin et al., 2004). 
From ancient times, in "urtication" therapy, people have used the sting of the fresh stinging nettle by flailing arthritic or paralytic limbs to induce blood circulation for warm joints and extremities Ancient Egyptians also used the injection for the alleviation of arthritis and lumbago (Harrison, 1961). "This practice of urtication or rubefaction became a standard in folk medicine as a remedy for arthritis, rheumatism, and muscular paralysis and is perhaps the most ancient medicinal use of stinging nettle" (Upton, 2013).

Evening primrose-Oenothera biennis is a wildflower that belongs to the Oenothera genus and has been grown as a beneficial herbal supplement. The entire plant was used by European settlers and Native Americans for Pain relief diseases such as bruising, stomachaches, and dyspnea (Tracy and Kingston, 2007). Evening primrose oil (EPO) is obtained from the seeds of Oenothera biennis L., Onagraceae. EPO has been recognized as an effective health care product (SafaaHussain et al., 2016).

EPO is an important source of omega- 6 essential fatty acids, especially polyunsaturated gamma-linolenic acid (18:3n-26, GLA). Previous studies have shown that EPO can be used as a remedy for the treatment of various disorders caused by GLA defects (SafaaHussain et al., 2016). GLA has anti-inflammatory, antithrombotic, and lipid-reducing activities. The $\Delta$-6-desaturase enzyme converts LA to GLA. Then, GLA changes to di-homo GLA (DGLA), which can be converted to prostaglandin E1 (PGE1), PGE2. $\triangle$-6desaturase enzyme activity decreases with age and in patients with arthritis, diabetes, hypertension, eczema, psoriasis. Limited in vivo generation of GLA has led to attention in the commercial production of EPO supplements (Khatri et al., 2012).

Furthermore, a diet rich in compounds containing GLA, which is being converted to DGLA, inhibits LT synthesis, LTB4 is one of the main products of arachidonic acid metabolism and stimulates chemokine synthesis in leukocytes, chemotaxis, adherence, and granulation. Moreover, LTB4 enhances the expression of C3b receptors. DGLA itself cannot be converted to LTs but can form a 15-hydroxyl derivative that blocks the conversion of arachidonic acid to LTs (Belch and Hill, 2000). EPO inhibits leukotriene synthesis because of its high amount of GLA (Montserrat-de la Paz et al., 2014).

Evening primrose is a wild plant of medicinal importance, EPO supplement is traditionally used for the treatment of eczema, asthma, rheumatoid arthritis, premenstrual and menopausal syndrome, atopic dermatitis, psoriasis, diabetic neuropathy, and other inflammation-related disorders (Bayles and Usatine, 2009, Stonemetz, 2008, Petrovska, 2012).

Treatment with GLA for 6 months resulted in statistically significant and clinically relevant reductions in the signs and symptoms of disease activity in patients with RA (Zurier et al., 1996). In our study, EPO showed a considerable decrease in morning stiffness and articular index (Brzeski et al., 1991).

However, the clinical documents of EPO consumption require to be studied by more meticulous investigations. 
So far, few studies have been performed to determine the beneficial effects of EPO and Urtica dioica on IL-17 production in patients with RA. Herein, we investigated the anti-inflammatory, anti-oxidant, and antirheumatic capacities of EPO and Urtica dioica in a randomized double-blind placebo-controlled clinical trial in people diagnosed with RA. Moreover, the clinical symptoms of patients with RA were assessed after EPO and Urtica dioica consumption. EPO and Urtica dioica have shown potent anti-inflammatory effects and reduced the complications of RA, thus considered as complementary medicines for RA and consequently reduces the disease symptoms.

The result of the present study showed that administration of 3 months EPO and Urtica dioica, in combination with conventional treatment, can significantly decrease the level of blood inflammatory markers, improve therapeutic benefits and decrease RA-related complications.

\section{Materials And Methods}

\subsection{Study Design}

This double-blind, randomized, placebo-controlled clinical trial was conducted on RA patients referred to a Rheumatologist's Clinic in Qazvin, Iran. The Rheumatologist and the patients were blinded to the groups. According to the sample size estimation formula with a test power of $90 \%, a$ of 0.05 and attrition of $20 \%$, the sample size was calculated for this clinical trial. The study groups included 90 patients with RA (78 female and 12 male). RA was diagnosed according to the revised 2010 American College of Rheumatology (ACR) criteria (Aletaha et al., 2010). The patients were randomly allocated to three groups: EPO, Stinging Nettle and Placebo (Barij Essence Pharmaceutical Company, Mashhad Ardehal, Kashan, Iran). The first group was taking 3 Evening Primrose oil soft capsules contains $500 \mathrm{mg}$ of EPO (Oenotherabiennis, seed) with $140 \mathrm{mg}$ of GLA daily after meals for three months. The second group received 3 Netonal Barij Tablets, contains $400 \mathrm{mg}$ of dried extract of Stinging Nettle leaves (Urtica dioica) with at least $1.3 \mathrm{mg}$ chlorogenic acid per tablet daily after meals for three months. The third group received the Placebo capsules 3 times a day for three months, representing the control group.

\subsection{Clinical and Laboratory Assessments}

A general questionnaire was used for collecting data, including demographic information. The clinical evaluation of disease activity was measured using the DAS28, which includes the 28 different joints for calculation (proximal interphalangeal joints, metacarpophalangeal joints, wrists, elbows, shoulders, and knees). The tender joint count (TJC), swollen joint count (SJC) and Visual Analogue Scale (VAS) were ascertained by a rheumatologist. The DAS28 also takes into account the erythrocyte sedimentation rate (ESR). The DAS28 score was calculated by the automatic DAS28 calculator V1.1- $\beta$ (Michiel, 2016).

Laboratory tests and clinical evaluations were performed on two occasions: before the EPO and Urtica dioica were administered and three months after the beginning of the study. 
Blood tests including Rheumatoid Factor (RF; cut-off value $14 \mathrm{lU} / \mathrm{ml}$ ), anti-cyclic citrullinated peptide antibodies (Anti-CCP; cut-off value $4.5 \mathrm{U} / \mathrm{ml}$ ), C-reactive protein (CRP; $\mathrm{mg} / \mathrm{L})$, ESR $(\mathrm{mm} / \mathrm{h}$ ), plasma levels of IL-17 cytokine and Total Anti-oxidant Capacity (TAC) were performed before and after treatments.

\subsection{Inclusion and Exclusion Criteria}

The RA patients gave their informed consent to participate in the study. The patients with cardiovascular, respiratory, kidney or hepatic diseases, patients under sex hormone therapy, those who were taking supplements prior to the intervention, those whose RA therapy had changed, those who were allergic to Nettle and those with other inflammatory diseases were excluded from the study.

\subsection{Ethics considerations}

This study was approved by the Research Ethics Committees of Qazvin University of Medical Sciences (IR.QUMS.REC.1395.312) Metabolic Diseases Research Center, Qazvin University of Medical Sciences, Qazvin, Iran. All RA patients were informed on the study and undersigned a written consent. The patients who no longer wanted to pursue their participation in the study at any stage exclude from it.

\subsection{Statistical Analysis}

The statistical data analysis was performed using SPSS20.0, considering $p$ value $\leq 0.05$ as significant. The results are presented as mean $\pm S D$. The Kolmogorov-Smirnov test was used to confirm the normal distribution of the data. The paired T Test was used to estimate changes from the baseline. Differences among the three tested groups at baseline and at the end of the study were assessed by one-way ANOVA followed by the Tukey Post Hoc Test.

\section{Results}

The present study was conducted to examine the effect of EPO and Urtica dioica on the clinical symptoms, laboratory parameters, TAC and IL-17 in patients with RA in a period of 3 months. The study groups included 90 patients aged $24-82$ years (mean age $49.95 \pm 12.46$ years) with RA. The mean duration ( \pm standard deviation) of the disease was $8.58 \pm 6.77$ years.

Patients were randomly divided into three groups, which were receiving the same anti-rheumatic therapy. During 3 months, the first group took EPO soft capsule, the second one took Nettle tablets and the third one took placebo. The details of the study selection process are presented in Figure 1. Patients' demographic characteristics are shown in Table 1. There were no considerable differences in the general characteristics of the patients between the EPO, Nettle and placebo groups at baseline. Table 2 represents 
the mean $\pm S D$ of DAS28, VAS, IL-17, TAC, RF, CRP, Anti-CCP, and ESR in each group at the end of the experiments compared to baseline (One-Way ANOVA). The differences of DAS28, IL-17, TAC, RF, and CRP between the 3 groups at baseline and at the end of the study were significant $(p \leq 0.05)$. Moreover, data was analyzed by paired T Tests to compare the differences between groups. Table 3 illustrates multiple comparisons with 95\% Confidence Interval (Tukey HSD). Post Hoc Tests results shows the significant differences between EPO and Nettle groups compared to Placebo group. There were significant differences in DAS28, RF, CRP, IL-17 and TAC between the EPO and Nettle groups compared the placebo group at the end of the study. DAS28, IL-17, CRP and RF are significantly reduced at the end of the experiment compared to the Placebo group. However, TAC significantly increased at the end of the study compared to the Placebo group. In placebo group, there were no statistically significant changes for serum markers and the clinical symptoms.

Anti-CCP and RF reduced significantly at the end of the experiment compared to the baseline in both groups, and this change was greater in the Nettle group than in the EPO group.

\section{Discussion}

The results of the present study showed that amelioration in several laboratory and clinical parameters in RA patients, who were taking EPO and Nettle along with the standard therapy. After 3 months, the findings showed that EPO and Nettle can significantly decrease the DAS28 score in RA patients compared to the placebo group.

Nevertheless, in our study supplementation with EPO and Nettle resulted in significantly improved clinical variables, the severity of pain and DAS28 score. Accordingly, a significant improvement in clinical and laboratory variables, were also observed in the supplemented groups.

There were no significant differences in the demographic characteristics of the RA patients between the three groups at beginning of the study. No adverse side effects were observed in this clinical trial after the use of EPO and Nettle.

To the best of our knowledge, this is the first study to evaluate the effects of EPO and Nettle on IL-17 production in RA patients. Our results have shown using of EPO and Nettle significantly reduced the IL-17 serum level. The results of the multiple comparisons in the present study showed that EPO and Nettle can help to relieve the clinical symptoms associated with RA.

For many years, using EPO supplements has been recommended as anti-oxidant and anti-inflammatory medicine in autoimmune and inflammatory diseases. EPO usually well tolerated by humans and no significant side effects have been documented in the medical literature. Since 1970, 1000 tons of EPO has been used daily in many countries, as yet, no dissatisfactions have been reported about its side effects. Also, many clinical trials have shown the beneficial effects of EPO on patients with diabetic neuropathy, hypertension, breast pain, premenstrual syndrome, osteoporosis and dementia (Petrovska, 2012, Bayles and Usatine, 2009, Stonemetz, 2008). 
GLA is one of the essential fatty acids, that should reach the body through supplements, which is present in EPO, increases the production of PGE1, which has anti-inflammatory properties and increased omega- 6 fatty acids (Bayles and Usatine, 2009, Timoszuk et al., 2018, Ghasemian et al., 2016).

The consumption of $1500 \mathrm{mg}$ of EPO/day for 3 months by the patients in group I resulted in significantly elevated TAC and decreased IL-17 serum levels.

Antioxidants play an essential role in the prevention of human diseases. Herbal medicines are the valuable source of free radical scavengers. It seems that this activity involved in therapeutic property of many herbal remedies. Oenothera biennis $L$. is the most important medicinal plant. Previous studied have shown that ethanolic extract of 0 . biennis L. represented strong antioxidant activity (Munir et al., 2017, SHAHIDI et al., 1997). Moreover, the triterpenoids found in methanol/water extract of 0 . biennis also have radical scavenging activity (Hamburger et al., 2002). The lipophilic triterpenoidal esters present in coldpressed, non-raffinated EPO were detected to be effective in reducing oxidative stress (Zaugg et al., 2006). The pressing residues from 0 . biennis were also found to possess a very high antioxidant activity (Peschel et al., 2007). Methanolic extract of the O. biennis seeds is a potent radical scavenger (Borchardt et al., 2009). Research showed that the alcoholic extract of oil seed cakes exhibited strong antioxidant capacity (Ratz-Lyko et al., 2013, Ahmad et al., 2014). The emulsions with O. biennis seedcake extracts have strong anti-inflammatory and antioxidant activity (Ratz Łyko et al., 2015).

EPO has anti-inflammatory effect, and it was found that EPO intake has prevented multiple sclerosis and several other inflammatory diseases (Zeng et al., 2013). Moreover, O. biennis was also found to have a potent anti-inflammatory action in the treatment of ulcerative colitis, Crohn's disease and also inflammatory bowel disease (Munir et al., 2017). EPO extracted by cold-pressed from O. biennis seeds is a main source of tocopherols, long-chain fatty alcohols and sterols. It was showed that the sterols present in the oil may have a protective effect on mediators involved in inflammation (Montserrat-de la Paz et al., 2012). The extracts of aerial parts of 0 . biennis exhibited anti-inflammatory activity by the inhibition of hyaluronidase and lipoxygenase in a dose-dependent manner (Granica et al., 2013).

Brzeski et al. carried out a prospective 6 months double-blind placebo-controlled study of dietary supplementation with GLA $540 \mathrm{mg} /$ day in RA patients. The results showed a significant reduction in morning stiffness with GLA at 3 months (Brzeski et al., 1991).

Jäntti et al. reported that use of $10 \mathrm{ml}$ EPO two times a day for 3 months significantly increases plasma prostaglandins concentration in patients with RA, however no significant clinical improvement has been reported (Jäntti et al., 1989).

A review study by Cameron et al. demonstrated that oils containing GLA (Primrose, borage, or Black Grape Seed Oil) can improve the RA symptoms (Cameron et al., 2011).

EPO is more known for its effects on systemic chronic inflammatory conditions, such as atopic dermatitis and RA. Hence, the significant decrease of the inflammatory parameters after GLA supplementation was 
expected (Khorshidi et al., 2020).

The anti-inflammatory property of stinging Nettle is due to inhibition of cytokine production, cyclooxygenase and lipoxygenase (Dhouibi et al., 2020, Capasso et al., 2003, Chrubasik et al., 2007). Shakibaei et al. explained that Nettle extracts have anti-inflammatory effects and decrease the IL- $\beta$ induced NF-kB activation in chondrocytes (Shakibaei et al., 2012). Hajhashemi study have demonstrated that the Urtica dioica' leaf extract has significant anti-inflammatory and analgesic effects and presents scientific evidence for its use in inflammatory diseases such as arthritis (Hajhashemi and Klooshani, 2013).

An alcoholic extract of Nettle leaves, significantly reduced proinflammatory cytokines production of TNF$a$ and IL-I in response to lipopolysaccharide (Dhouibi et al., 2020). A study on human blood have shown that an aqueous alcoholic extract of Nettle leaves after $24 \mathrm{~h}$, reduced the levels of TNF- $\mathrm{a}$ and IL-I by $50.8 \%$ and $99.7 \%$, respectively. Moreover, previous studies have reported that an alcoholic extract inhibited the exocytosis of neutrophil elastase and Platelet Activating Factor (PAF) (Barnes et al., 2002, Escop and Phytotherapy, 2003).

Riehemann and Schulze-Osthoff demonstrated that in vitro Nettle leaf extract strongly suppressed the activation of NF-kappa in human T lymphocytes, macrophages and epithelial cells (Riehemann et al., 1999). It seems that the inhibitory effect of Nettle on NF-kappa B activation involved in the antiinflammatory effects of Nettle (Barnes et al., 2002).

An aqueous extract of Nettle leaves inhibits the IL-2 expression in Th1 cells stimulated by phytohemagglutinins, and suppress IFNy production in mononuclear cells culture in a dose-dependent manner. In contrast, production of IL-4 stimulated by Th2 cells. Therefore, the Nettle leaves extract downregulates inflammation through inhibition of cytokines of T lymphocytes in autoimmune diseases such as RA (Barnes et al., 2002, Escop and Phytotherapy, 2003).

In a study, which has been conducted on patients with RA by Chrubasik et al. demonstrated that Nettle leaves decrease CRP, and clinical symptoms of acute arthritis (stiffness and pressure pain) in patients with severe arthritis (Chrubasik et al., 1997). It was concluded that administration of Nettle leaves could enhance the effectiveness of anti-inflammatory drugs used as anti-rheumatic.

Leaves extract of Urtica dioica has been used as anti-inflammatory medicines due to its inhibitory effect on NF-kB activation in RA and suppression of cytokine production. Inhibition of NF-kB activation involved in the anti-inflammatory effect of the plant (Joshi et al., 2014).

Nettle herb is recommended for complaints associated with RA, osteoarthritis and urinary tract infections (Chrubasik et al., 2007).

In this regard, our study gives substantial contribution to recommendation for the use of EPO and Nettle in RA patients. This study added EPO and Nettle to RA patients' treatment regimen in a double-blinded clinical trial. This addition proved to be safe and effective in the management of the clinical and 
laboratory parameters of the patients compared to baseline. The present study used a new formulation of EPO and Nettle (Barij Essence Pharmaceutical Company, Mashhad Ardehal, Kashan, Iran) for the first time and observed an improvement in the patients' clinical symptoms. Further studies are proposed to be conducted on a larger sample size of RA patients for a longer duration and with a higher dose of EPO and Nettle.

\section{Conclusion}

In conclusion, the intake of EPO and Nettle resulted in production of the anti-inflammatory mediators in plasma. This further induced a significant improvement in the clinical status of patients with RA. Besides, we have shown that the consumption of Nettle also had positive effects in patients with RA, which were better than the EPO. According to the results of this study, it seems that EPO and Nettle can be used as safe supplements for control and improvement of clinical and laboratory parameters of RA disease. However, further well-designed investigation with larger sample size over a longer duration are warranted to evaluate and determine the efficacy and optimal dose of EPO and Nettle for managing the RA patients' symptoms and confirm the long-term efficacy of these supplementations. Thus, Nettle and EPO have a great potential as a complementary therapy in patients with RA and other chronic inflammatory diseases.

\section{Abbreviations}

RA: Rheumatoid arthritis; EPO: Evening Primrose Oil; DAS 28: Disease Activity Score 28; VAS: Visual Analogue Scale; TAC: Total Anti-oxidant Capacity; IL-17: Interleukin-17; RF: Rheumatoid Factor; Anti-CCP: Anti-cyclic citrullinated peptide antibodies; CRP: C Reactive Protein; ESR: Erythrocyte Sedimentation Rate;

STAT4: Signal transducer and activator of transcription 4; PTPN22: Protein tyrosine phosphatase; PAD1,4: peptidyl arginine deiminase type I, IV; CTLA4: Cytotoxic T-lymphocyte antigen 4; NSAIDs: Nonsteroidal anti-inflammatory drugs; DMARDs: Disease-modifying anti-rheumatic drugs; JAK: Janus kinase; LDAS: Disease activity state; CAMs: Complementary and alternative medicines; GLA: gamma-linolenic acid; PGE1: Prostaglandin E1; ACR: American College of Rheumatology; TJC: Tender joint count; SJC: Swollen joint count.

\section{Declarations}

\section{Ethics approval and Consent to participate}

This clinical trial was conducted in compliance with the Declaration of Helsinki, International Council for Harmonization Guidelines for Good Clinical Practice, and local country regulations. All patients provided written informed consent to participate in the respective studies. Ethical approval was received from the Qazvin University of Medical Sciences Ethics Committee (IR.QUMS.REC.1395.312).

\section{Consent for Publication}


Not applicable.

\section{Availability of Supporting data}

The supporting materials used in this study are contained within the article. The data analyzed during the current investigation are not publicly available. We are committed to sharing with qualified external researchers' access to patient-level data and supporting clinical documents from eligible studies. These requests are reviewed and approved based on scientific merit. All data provided are anonymized to respect the privacy of patients who have participated in the trial in line with applicable laws and regulations. The data may be requested from the corresponding author of the manuscript.

\section{Competing Interests}

The authors declare they have no conflicts of interest.

\section{Funding}

This study was supported by Metabolic Diseases Research Center, Qazvin University of Medical Sciences, Qazvin, Iran (IR.QUMS.REC.1395.312).

\section{Authors' contributions}

All authors were involved in the drafting and revision of the manuscript and approved the final version for submission. BAN, MA, and SAF were involved in the acquisition of clinical and laboratory data and participated in data collection reported in the manuscript. BAN was involved with the conception or design of the work and the development of the statistical analysis plan. MM was involved in the formulation and preparation of herbal medicines for RA patients. BAN and ADS were involved with the interpretation of data in the manuscript. BAN, AJ, and ADS were involved with the analysis of the data in the manuscript. All authors agreed to be accountable for all aspects of the work and attested to the accuracy and integrity of the work.

\section{Acknowledgments}

The authors are thankful to the Vice Chancellor of Research of Qazvin University of Medical Sciences for their support.

\section{References}

AHMAD, A., SINGH, D. K., FATIMA, K., TANDON, S. \& LUQMAN, S. 2014. New constituents from the roots of Oenothera biennis and their free radical scavenging and ferric reducing activity. Industrial Crops and Products, 58, 125-132.

AL-SAADANY, H., HUSSEIN, M., GABER, R. \& ZAYTOUN, H. Th-17 cells and serum IL-17 in rheumatoid arthritis patients: Correlation with disease activity and severity. Egypt Rheumatol. 2016; 38: 1-7. 
ALETAHA, D., NEOGI, T., SILMAN, A. J., FUNOVITS, J., FELSON, D. T., BINGHAM III, C. O., BIRNBAUM, N. S., BURMESTER, G. R., BYKERK, V. P. \& COHEN, M. D. 2010. 2010 rheumatoid arthritis classification criteria: an American College of Rheumatology/European League Against Rheumatism collaborative initiative. Arthritis \& rheumatism, 62, 2569-2581.

ALSHUWAYEB, M. H. \& AL-KHATIB, A. J. 2013. Molecular and chemical therapeutic features of Urtica species. European scientific journal, 9.

BARNES, J., ANDERSON, L. A. \& PHILLIPSON, J. D. 2002. Herbal medicines: Joanne Barnes, Linda A. Anderson, J. David Phillipson. a guide for healthcare professionals.

BAYLES, B. \& USATINE, R. 2009. Evening primrose oil. American family physician, 80, 1405-1408.

BELCH, J. J. \& HILL, A. 2000. Evening primrose oil and borage oil in rheumatologic conditions. The American journal of clinical nutrition, 71, 352s-356s.

BNOUHAM, M., MEKHFI, H., LEGSSYER, A. \& ZIYYAT, A. 2002. Ethnopharmacology Forum Medicinal plants used in the treatment of diabetes in Morocco. Int. J. Diabetes Metab, 10, 33-50.

BORCHARDT, J. R., WYSE, D. L., SHEAFFER, C. C., KAUPPI, K. L., FULCHER, R. G., EHLKE, N. J., BIESBOER, D. D. \& BEY, R. F. 2009. Antioxidant and antimicrobial activity of seed from plants of the Mississippi river basin. Journal of Medicinal Plants Research, 3, 707-718.

BRZESKI, M., MADHOK, R. \& CAPELL, H. 1991. Evening primrose oil in patients with rheumatoid arthritis and side-effects of non-steroidal anti-inflammatory drugs. Rheumatology, 30, 370-372.

BURMESTER, G. R. \& POPE, J. E. 2017. Novel treatment strategies in rheumatoid arthritis. The Lancet, $389,2338-2348$.

CAMERON, M., GAGNIER, J. J. \& CHRUBASIK, S. 2011. Herbal therapy for treating rheumatoid arthritis. Cochrane Database of Systematic Reviews.

CAPASSO, F., GAGINELLA, T. S., GRANDOLINI, G. \& IZZO, A. A. 2003. Phytotherapy: a quick reference to herbal medicine, Springer Science \& Business Media.

CHOY, E. 2012. Understanding the dynamics: pathways involved in the pathogenesis of rheumatoid arthritis. Rheumatology, 51, v3-v11.

CHRUBASIK, J. E., ROUFOGALIS, B. D., WAGNER, H. \& CHRUBASIK, S. A. 2007. A comprehensive review on nettle effect and efficacy profiles, Part I: herba urticae. Phytomedicine, 14, 423-435.

CHRUBASIK, S., ENDERLEIN, W., BAUER, R. \& GRABNER, W. 1997. Evidence for antirheumatic effectiveness of Herba Urticae dioicae in acute arthritis: A pilot study. Phytomedicine, 4, 105-108. 
DAOUDI, A., BENBOUBKER, H., BOUSTA, D. \& AARAB, L. 2008. Screening of fourteen, Moroccan medicinal plants for immunomodulating activities. Moroccan J Biol, 1, 24-30.

DHOUIBI, R., AFFES, H., SALEM, M. B., HAMMAMI, S., SAHNOUN, Z., ZEGHAL, K. M. \& KSOUDA, K. 2020. Screening of pharmacological uses of Urtica dioica and others benefits. Progress in biophysics and molecular biology, 150, 67-77.

EKOR, M. 2014. The growing use of herbal medicines: issues relating to adverse reactions and challenges in monitoring safety. Frontiers in pharmacology, 4, 177.

ESCOP \& PHYTOTHERAPY, E. S. C. O. 2003. ESCOP Monographs: the scientific foundation for herbal medicinal products, Thieme.

FOROUZANFAR, F. \& HOSSEINZADEH, H. 2018. Medicinal herbs in the treatment of neuropathic pain: a review. Iranian journal of basic medical sciences, $21,347$.

GHASEMIAN, M., OWLIA, S. \& OWLIA, M. B. 2016. Review of anti-inflammatory herbal medicines. Advances in pharmacological sciences, 2016.

GRANICA, S., CZERWIŃSKA, M. E., PIWOWARSKI, J. P., ZIAJA, M. \& KISS, A. K. 2013. Chemical composition, antioxidative and anti-inflammatory activity of extracts prepared from aerial parts of Oenothera biennis L. and Oenothera paradoxa Hudziok obtained after seeds cultivation. Journal of agricultural and food chemistry, 61, 801-810.

GÜLÇIN, I., KÜFREVIOGLU, Ö. İ., OKTAY, M. \& BÜYÜKOKUROGLU, M. E. 2004. Antioxidant, antimicrobial, antiulcer and analgesic activities of nettle (Urtica dioica L.). Journal of ethnopharmacology, 90, 205-215.

GUO, Q., WANG, Y., XU, D., NOSSENT, J., PAVLOS, N. J. \& XU, J. 2018. Rheumatoid arthritis: pathological mechanisms and modern pharmacologic therapies. Bone research, 6, 1-14.

HAJHASHEMI, V. \& KLOOSHANI, V. 2013. Antinociceptive and anti-inflammatory effects of Urtica dioica leaf extract in animal models. Avicenna journal of phytomedicine, 3, 193.

HAMBURGER, M., RIESE, U., GRAF, H., MELZIG, M. F., CIESIELSKI, S., BAUMANN, D., DITTMANN, K. \& WEGNER, C. 2002. Constituents in evening primrose oil with radical scavenging, cyclooxygenase, and neutrophil elastase inhibitory activities. Journal of agricultural and food chemistry, 50, 5533-5538.

HARRISON, R. K. 1961. Healing herbs of the Bible, EJ Brill Leiden.

JÄNTTI, J., SEPPÄLÄ, E., VAPAATALO, H. \& ISOMÄKI, H. 1989. Evening primrose oil and olive oil in treatment of rheumatoid arthritis. Clinical rheumatology, 8, 238-244.

JOSHI, B. C., MUKHIJA, M. \& KALIA, A. N. 2014. Pharmacognostical review of Urtica dioica L. International Journal of Green Pharmacy (IJGP), 8. 
KHATRI, S., YADAV, S. \& SHARMA, V. 2012. Importance of -Linolenic Acid in Clinical Indications. International Journal of Therapeutic Applications, 2, 33-42.

KHORSHIDI, M., ZAREZADEH, M., MORADI MOGHADDAM, O., EMAMI, M. R., KORD-VARKANEH, H., MOUSAVI, S. M., ALIZADEH, S., HESHMATI, J., OLANG, B. \& ARYAEIAN, N. 2020. Effect of evening primrose oil supplementation on lipid profile: A systematic review and meta-analysis of randomized clinical trials. Phytotherapy Research.

KLINGELHOEFER, S., OBERTREIS, B., QUAST, S. \& BEHNKE, B. 1999. Antirheumatic effect of IDS 23, a stinging nettle leaf extract, on in vitro expression of T helper cytokines. The Journal of rheumatology, 26, 2517.

LI, T.-P., ZHANG, A.-H., MIAO, J.-H., SUN, H., YAN, G.-L., WU, F.-F. \& WANG, X.-J. 2019. Applications and potential mechanisms of herbal medicines for rheumatoid arthritis treatment: a systematic review. RSC advances, 9, 26381-26392.

MCINNES, I. B. \& SCHETT, G. 2007. Cytokines in the pathogenesis of rheumatoid arthritis. Nature Reviews Immunology, 7, 429-442.

MICHIEL, A. A. 2016. DAS 28 calculator V1.1-beta [Online]. Available: http://www.umcn.nl.DAS28 [Accessed 5 March 2016].

MONTSERRAT-DE LA PAZ, S., FERNÁNDEZ-ARCHE, Á., ÁNGEL-MARTÍN, M. \& GARCÍA-GIMÉNEZ, M. D. 2012. The sterols isolated from Evening Primrose oil modulate the release of proinflammatory mediators. Phytomedicine, 19, 1072-1076.

MONTSERRAT-DE LA PAZ, S., FERNANDEZ-ARCHE, M., ANGEL-MARTIN, M. \& GARCIA-GIMENEZ, M. 2014. Phytochemical characterization of potential nutraceutical ingredients from Evening Primrose oil (Oenothera biennis L.). Phytochemistry Letters, 8, 158-162.

MUNIR, R., SEMMAR, N., FARMAN, M. \& AHMAD, N. S. 2017. An updated review on pharmacological activities and phytochemical constituents of evening primrose (genus Oenothera). Asian Pacific Journal of Tropical Biomedicine, 7, 1046-1054.

OMETTO, F., BOTSIOS, C., RAFFEINER, B., SFRISO, P., BERNARDI, L., TODESCO, S., DORIA, A. \& PUNZI, L. 2010. Methods used to assess remission and low disease activity in rheumatoid arthritis. Autoimmunity reviews, 9, 161-164.

PESCHEL, W., DIECKMANN, W., SONNENSCHEIN, M. \& PLESCHER, A. 2007. High antioxidant potential of pressing residues from evening primrose in comparison to other oilseed cakes and plant antioxidants. Industrial Crops and Products, 25, 44-54.

PETROVSKA, B. B. 2012. Historical review of medicinal plants' usage. Pharmacognosy reviews, 6, 1. 
RATZ-ŁYKO, A., ARCT, J., PYTKOWSKA, K. \& MAJEWSKI, S. 2015. In vivo and ex vivo evaluation of cosmetic properties of seedcakes. Journal of Cosmetic and Laser Therapy, 17, 109-115.

RATZ-LYKO, A., ARCT, J., PYTKOWSKA, K., MAJEWSKI, S. \& BREGISZ, M. 2013. Effect of enzymatic hydrolysis on the antioxidant properties of alcoholic extracts of oilseed cakes. Food Technology and Biotechnology, 51, 539.

RIEHEMANN, K., BEHNKE, B. \& SCHULZE-OSTHOFF, K. 1999. Plant extracts from stinging nettle (Urtica dioica), an antirheumatic remedy, inhibit the proinflammatory transcription factor NF-KB. FEBS letters, 442, 89-94.

ROBERT, M. \& MIOSSEC, P. 2019. IL-17 in rheumatoid arthritis and precision medicine: from synovitis expression to circulating bioactive levels. Frontiers in medicine, 5, 364.

SAFAAHUSSAIN, M., ABDULRIDHA, M. K. \& KHUDHAIR, M. S. 2016. Anti-inflammatory, Anti-oxidant, and Vasodilating Effect of Evening Primrose Oil in Type 2 Diabetic Patients. Int. J. Pharm. Sci. Rev. Res, 39, 173-178.

SHAHIDI, F., AMAROWICZ, R., HE, Y. \& WETTASINGHE, M. 1997. Antioxidant activity of phenolic extracts of evening primrose (Oenothera biennis): A preliminary study. Journal of Food Lipids, 4, 75-86.

SHAKIBAEI, M., ALLAWAY, D., NEBRICH, S. \& MOBASHERI, A. 2012. Botanical Extracts from Rosehip (Rosa canina), Willow bark (Salix alba), and Nettle Leaf (Urtica dioica) suppress IL-1-Induced NF-KB activation in canine articular chondrocytes. Evidence-Based Complementary and Alternative Medicine, 2012.

STONEMETZ, D. 2008. A review of the clinical efficacy of evening primrose. Holistic nursing practice, 22, 171-174.

SUNG, S., KWON, D., UM, E. \& KIM, B. 2019. Could polyphenols help in the control of rheumatoid arthritis? Molecules, 24, 1589.

TAAMS, L. S. 2020. Interleukin-17 in rheumatoid arthritis: Trials and tribulations. Journal of Experimental Medicine, 217.

TESTAI, L., CHERICONI, S., CALDERONE, V., NENCIONI, G., NIERI, P., MORELLI, I. \& MARTINOTTI, E. 2002. Cardiovascular effects of Urtica dioica L.(Urticaceae) roots extracts: in vitro and in vivo pharmacological studies. Journal of Ethnopharmacology, 81, 105-109.

TIMOSZUK, M., BIELAWSKA, K. \& SKRZYDLEWSKA, E. 2018. Evening primrose (Oenothera biennis) biological activity dependent on chemical composition. Antioxidants, 7, 108.

TRACY, T. S. \& KINGSTON, R. L. 2007. Herbal products: toxicology and clinical pharmacology, Springer Science \& Business Media. 
UPTON, R. 2013. Stinging nettles leaf (Urtica dioica L.): Extraordinary vegetable medicine. Journal of Herbal Medicine, 3, 9-38.

VIATTE, S., PLANT, D. \& RAYCHAUDHURI, S. 2013. Genetics and epigenetics of rheumatoid arthritis. Nature Reviews Rheumatology, 9, 141.

ZAUGG, J., POTTERAT, O., PLESCHER, A., HONERMEIER, B. \& HAMBURGER, M. 2006. Quantitative analysis of anti-inflammatory and radical scavenging triterpenoid esters in evening primrose seeds. Journal of agricultural and food chemistry, 54, 6623-6628.

ZENG, G., JU, Y., SHEN, H., ZHOU, N. \& HUANG, L. 2013. Immunopontentiating activities of the purified polysaccharide from evening primrose in $\mathrm{H} 22$ tumor-bearing mice. International journal of biological macromolecules, 52, 280-285.

ZHAO, S., OTIENO, F., AKPAN, A. \& MOOTS, R. J. 2017. Complementary and alternative medicine use in rheumatoid arthritis: considerations for the pharmacological management of elderly patients. Drugs \& aging, 34, 255-264.

ZURIER, R. B., ROSSETTI, R. G., JACOBSON, E. W., DEMARCO, D. M., LIU, N. Y., TEMMING, J. E., WHITE, B. M. \& LAPOSATA, M. 1996. Gamma-linolenic acid treatment of rheumatoid arthritis. A randomized, placebo-controlled trial. Arthritis \& Rheumatism, 39, 1808-1817.

\section{Tables}

Table 1. Demographic characteristics of the patients with RA.

\begin{tabular}{|lllll|}
\hline Patients' Characteristics & $\begin{array}{l}\text { Group I } \\
(\text { EPO) }\end{array}$ & $\begin{array}{l}\text { Group II } \\
\text { (Nettle) }\end{array}$ & $\begin{array}{l}\text { Group III } \\
\text { (Placebo) }\end{array}$ & Total \\
\cline { 2 - 5 } & $\mathbf{N = 2 9}$ & $\mathbf{N = 3 1}$ & $\mathbf{N}=\mathbf{3 0}$ & $\mathbf{N}=\mathbf{9 0}$ \\
\hline Age $(\mathbf{X} \pm$ SD; years) & $48.10 \pm 11.72$ & $50.26 \pm 13.74$ & $51.43 \pm 11.97$ & $49.95 \pm 12.46$ \\
\hline Disease duration & $8.43 \pm 6.59$ & $9.36 \pm 7.76$ & $7.92 \pm 5.97$ & $8.58 \pm 6.78$ \\
\hline Gender N (\%) & & & & \\
\hline Female & $26(89.7)$ & $25(80.6)$ & $27(90.0)$ & 78 \\
\hline Male & $3(10.3)$ & $6(19.4)$ & $3(10.0)$ & 12 \\
\hline
\end{tabular}

Note: Data are expressed as the mean \pm SD

No considerable differences, assessed by one-way ANOVA. 
Table 2. Clinical symptoms and laboratory parameters of participants in EPO, Nettle and placebo groups. 


\begin{tabular}{|c|c|c|c|c|c|}
\hline \multirow[t]{2}{*}{$\begin{array}{l}\text { Patients' } \\
\text { Characteristics }\end{array}$} & \multirow[t]{2}{*}{ Timing } & $\begin{array}{l}\text { Group I } \\
\text { (EPO) }\end{array}$ & $\begin{array}{l}\text { Group II } \\
\text { (Nettle) }\end{array}$ & $\begin{array}{l}\text { Group III } \\
\text { (Placebo) }\end{array}$ & $\begin{array}{l}\text { One- } \\
\text { Way } \\
\text { ANOVA }\end{array}$ \\
\hline & & $\mathrm{N}=29$ & $N=31$ & $\mathrm{~N}=30$ & \\
\hline \multirow[t]{2}{*}{ CRP } & Baseline & $7.29 \pm 5.061$ & $12.38 \pm 21.60$ & $6.96 \pm 5.50$ & .214 \\
\hline & $\begin{array}{l}\text { End of } \\
\text { study }\end{array}$ & $3.51 \pm 2.09$ & $4.41 \pm 5.10$ & $7.26 \pm 5.64$ & $.006^{*}$ \\
\hline \multicolumn{2}{|c|}{$P$ value (Paired sample t test) } & $.000 *$ & $.016^{\star}$ & .748 & \\
\hline \multirow[t]{2}{*}{ ESR } & Baseline & $20.27 \pm 13.27$ & $26.48 \pm 19.10$ & $18.56 \pm 15.43$ & .138 \\
\hline & $\begin{array}{l}\text { End of } \\
\text { study }\end{array}$ & $12.82 \pm 9.71$ & $13.93 \pm 8.55$ & $17.96 \pm 10.91$ & .108 \\
\hline \multicolumn{2}{|c|}{$P$ value (Paired sample t test) } & $.000 *$ & $.000 *$ & .805 & \\
\hline \multirow[t]{2}{*}{ Anti-CCP } & Baseline & $196.50 \pm 198.25$ & $314.47 \pm 446.83$ & $161.85 \pm 156.94$ & .119 \\
\hline & $\begin{array}{l}\text { End of } \\
\text { study }\end{array}$ & $111.42 \pm 100.16$ & $102.40 \pm 105.73$ & $218.87 \pm 404.26$ & .135 \\
\hline \multicolumn{2}{|c|}{$P$ value (Paired sample t test) } & $.010 *$ & $.006^{\star}$ & .443 & \\
\hline \multirow[t]{2}{*}{ DAS 28} & Baseline & $3.11 \pm .98$ & $3.58 \pm 1.16$ & $2.85 \pm 1.25$ & $.045^{\star}$ \\
\hline & $\begin{array}{l}\text { End of } \\
\text { study }\end{array}$ & $2.41 \pm .81$ & $2.48 \pm .95$ & $3.16 \pm 1.06$ & $.005^{\star}$ \\
\hline \multicolumn{2}{|c|}{$P$ value (Paired sample t test) } & $.000 *$ & $.000 *$ & .05 & \\
\hline \multirow[t]{2}{*}{ IL-17 } & Baseline & $165.76 \pm 41.19$ & $153.69 \pm 38.16$ & $137.04 \pm 22.21$ & $.008^{\star}$ \\
\hline & $\begin{array}{l}\text { End of } \\
\text { study }\end{array}$ & $124.34 \pm 30.38$ & $97.57 \pm 26.09$ & $142.68 \pm 31.38$ & $.000 *$ \\
\hline \multicolumn{2}{|c|}{$P$ value (Paired sample t test) } & $.000 *$ & $.000 *$ & .361 & \\
\hline \multirow[t]{2}{*}{ TAC } & Baseline & $290.32 \pm 67.89$ & $282.80 \pm 51.19$ & $272.77 \pm 47.52$ & .485 \\
\hline & $\begin{array}{l}\text { End of } \\
\text { study }\end{array}$ & $386.97 \pm 60.78$ & $407.66 \pm 54.91$ & $281.75 \pm 46.53$ & $.000 *$ \\
\hline \multicolumn{2}{|c|}{$P$ value (Paired sample t test) } & $.000 *$ & $.000 *$ & .170 & \\
\hline \multirow[t]{2}{*}{ RF } & Baseline & $1.24 \pm 1.27$ & $5.49 \pm 22.09$ & $1.66 \pm 1.15$ & .377 \\
\hline & $\begin{array}{l}\text { End of } \\
\text { study }\end{array}$ & $.65 \pm .81$ & $.66 \pm .75$ & $1.33 \pm 1.12$ & $.006 *$ \\
\hline \multicolumn{2}{|c|}{$P$ value (Paired sample t test) } & $.002 *$ & $.000 *$ & $.039 *$ & \\
\hline VAS & Baseline & $4.17 \pm 2.67$ & $4.97 \pm 2.85$ & $4.06 \pm 3.09$ & .414 \\
\hline
\end{tabular}




\begin{tabular}{|c|c|c|c|}
\hline $\begin{array}{l}\text { End of } \\
\text { study }\end{array}$ & $1.55 \pm 1.97$ & $2.36 \pm 2.48$ & $2.76 \pm 2.69$ \\
\hline$P$ value (Paired sample t test) & $.000 *$ & $.000 *$ & $.023 *$ \\
\hline
\end{tabular}

Values are expressed as mean \pm SD.

Paired Samples Test, 95\%, Confidence Interval of the Difference (Sig. 2-tailed).

Table 3 Multiple Comparisons (95\% Confidence Interval) at the end of study. Tukey HSD

\begin{tabular}{|c|c|c|c|}
\hline Dependent Variable & & & Sig. \\
\hline \multirow[t]{3}{*}{ DAS28 } & \multirow[t]{2}{*}{ Placebo } & Nettle & $.019 *$ \\
\hline & & EPO & $.010^{\star}$ \\
\hline & EPO & Nettle & .956 \\
\hline \multirow[t]{3}{*}{ RF } & \multirow[t]{2}{*}{ Placebo } & Nettle & $.016 *$ \\
\hline & & EPO & $.015^{\star}$ \\
\hline & EPO & Nettle & .999 \\
\hline \multirow[t]{3}{*}{ CRP } & \multirow[t]{2}{*}{ Placebo } & Nettle & $.045^{\star}$ \\
\hline & & EPO & $.006^{*}$ \\
\hline & EPO & Nettle & .727 \\
\hline \multirow[t]{3}{*}{ IL-17 } & \multirow[t]{2}{*}{ Placebo } & Nettle & $.000 *$ \\
\hline & & EPO & $.048^{*}$ \\
\hline & EPO & Nettle & $.002 *$ \\
\hline \multirow[t]{3}{*}{ TAC } & \multirow[t]{2}{*}{ Placebo } & Nettle & $.000 *$ \\
\hline & & EPO & $.000 *$ \\
\hline & EPO & Nettle & .308 \\
\hline
\end{tabular}

* The mean difference is significant at the 0.05 level.

\section{Figures}




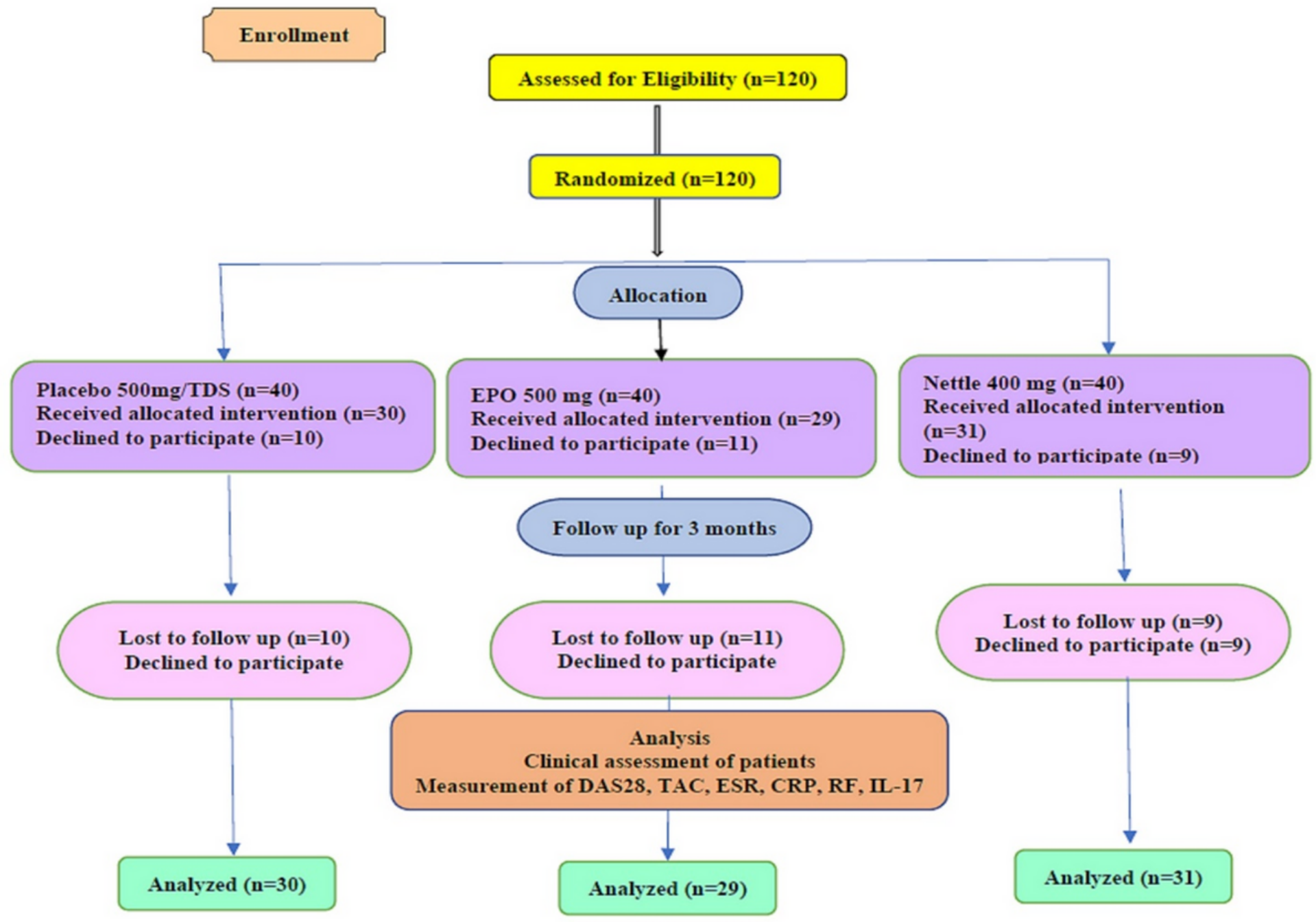

\section{Figure 1}

The flow diagram of the study. TDS, three times a day. 